\title{
Procedimentos de enfermagem no paciente portador de úlcera de pressão
}

\author{
Rosiléia Dias Domingos*, Cláudia de Souza Moraes, M.Sc.**
}

${ }^{*}$ Curso de Graduação em Enfermagem do Centro Universitário Celso Lisboa, ${ }^{* *}$ Orientadora, UERJ

\begin{abstract}
Resumo
A úlcera de pressáo pode ser definida como uma área localizada de necrose celular que tende a desenvolver-se quando os tecidos moles são comprimidos entre uma proeminência óssea e uma superfície dura por um período prolongado de tempo e sua prevenção e tratamento constituem um grande desafio para a enfermagem. Os fatores de risco que podem causar a úlcera de pressão são os externos (pressão, cisalhamento, fricção) e internos - condiçốes nutricionais; idade avançada; incontinência urinária ou fecal; mobilidade reduzida ou ausente; peso corporal - menos tecido adiposo, menor proteção nas proeminências ósseas; doenças - diabetes, hipertensão, doença vascular periférica, câncer e outras; uso de medicamentos - antibióticos, corticóide, aminas, entre outros. Para mostrar como deve ser o procedimento de enfermagem em relação ao indivíduo com úlcera de pressão, optou-se por realizar um estudo de caso hipotético-dedutivo de um paciente portador de trauma raquimedular. Concluiu-se que é importante que seja adotada uma rotina pré-estabelecida de técnicas e tipos de curativos para tratamento das úlceras de pressão em regiâo sacra, visto que a uniformizaçáo das açóes contribuirá para o controle e acompanhamento adequados das lesóes, propiciando melhor prognóstico, o que facilitará as açóes de enfermagem.
\end{abstract}

Palavras-chave: úlcera de pressão, procedimento, enfermagem.

\section{Abstract}

\section{Nursing procedures to care patient with pressure ulcer}

The pressure ulcer can be defined as a localized area of cellular necrosis resulting from direct pressure on the skin between bony prominence and hard surface for prolonged period. Its prevention and treatment is a great challenge for nursing. Risk factors which can cause pressure ulcer are external (pressure, shear, friction) and internal (impaired nutrition, increasing age, urinary or fecal incontinence; impaired mobility, body mass - less adipose tissue, lesser bony prominence protection; disease - diabetes, hypertension, peripheral vascular disease, cancer and others; medicine use - antibiotic, corticoid, amine and others. To show how nursing procedures should be performed to an individual with pressure ulcer, we decided to carry out a case study using a hypothetical-deductive model of a patient with spinal cord injury. We conclude that it is important that a daily established routine of techniques and types of dressings for treatment of sacral pressure ulcers should be adopted, as uniform procedures will cooperate for adequate wound management and follow up, providing better prognosis and making easier nursing actions.

Key-words: pressure ulcer, procedure, nursing. 


\section{Resumen}

\section{Procedimientos de enfermería al paciente con úlcera por presión}

La úlcera por presión puede definirse como cualquier área de daño en la piel y tejido subyacente causado por la presión prolongada sobre un plano duro y su prevención y tratamiento constituyen un desafío para la enfermería. Los factores de riesgo que pueden causar ulcera por presión pueden ser externos (presión, cizallamiento, fricción) y externos - condiciones nutricionales; edad avanzada; incontinencia urinaria o fecal, movilidad reducida o ausente; peso corporal - menos tejido adiposo, menor protección en las prominencias óseas; enfermedades - diabetes, hipertensión, enfermedad vascular periférica, cáncer y otras; uso de medicamentos - antibióticos, corticoides, aminas, entre otros. Para demostrar como debe ser el procedimiento de enfermería en relación al individuo con úlcera por presión, se optó por realizar un estudio de caso hipotético deductivo de un paciente con trauma raquimedular. Se concluyó que es importante que sea pre-establecida una rutina de técnicas y tipos de curativos para tratamiento de úlcera por presión en región sacra, una vez que, la uniformidad en los procedimientos contribuirá para el control y seguimiento adecuados de las heridas, proporcionando mejor pronostico, y así facilitar las acciones de enfermería.

Palabras-claves: úlcera por presión, procedimiento, enfermería.

\section{Introdução}

A enfermagem é uma profissão em que pessoas especializadas cuidam dos doentes, ajudando-os a recuperar a saúde. A maioria desses profissionais trabalha em hospitais, mas há os que atuam em outros lugares. Estes podem prestar cuidados em doentes em domicílio, nos consultórios (de médicos e/ou dentistas), nas policlínicas, clubes, escolas, fábricas, nas forças armadas, e em navios, trens ou aviōes dos serviços de saúde (civis ou militares), nas grandes e pequenas cidades, na zona rural, nas missões religiosas e serviços de proteção ao índio, em suma, em todas as partes do mundo.

Pensando em todos os lugares e condiçóes de trabalho do enfermeiro, resolveu-se neste trabalho esclarecer pontos sobre a úlcera de pressão em seu tratamento e condiçóes dos pacientes/curativos; sabendo-se que a úlcera acontece pela perda de substâncias superficiais da epiderme ou da mucosa, geralmente com pouca tendência à cicatrização, causada de regra por perturbaçóes circulatórias, irritaçáo persistente e imobilidade prolongada. $\mathrm{O}$ ideal é fazer uma rotina de curativo para a úlcera de pressão de acordo com o que a instituição oferece, náo se esquecendo de realizar tratamento local cuidadoso (curativos à base de antibiótico, vitaminas e substâncias cicatrizantes).

A literatura internacional aponta que entre 3 a $14 \%$ de todos os pacientes hospitalizados desenvolvem lesóes de pele. Vale lembrar que algumas delas são decorrentes de fatores inerentes à doença e às condições clínicas do cliente e que, muitas vezes, podem ser evitadas com o uso de materiais e equipamentos adequados ao alívio da pressão e aos cuidados específicos com a pele.

A prevenção e o tratamento das úlceras de pressão constituem um grande desafio para a enfermagem, principalmente porque a ocorrência de lesôes aumenta a propensão do cliente a apresentar infecções, interfere na qualidade de vida, eleva o índice de permanência nos leitos hospitalares e, conseqüentemente, interfere no custo hospitalar.

Segundo Rabeh [1], desde Florence Nightingale, período caracterizado como Enfermagem Moderna, a ocorrência da úlcera de pressáo tem uma conotação negativa, apresentando-se como falha no cuidado ou assistência inadequada. No livro Notas sobre a enfermagem, a autora evidencia que: "Se o doente sente frio, apresenta-se febril, sofre desfalecimentos, sente-se mal após as refeiçôes, ou ainda se apresenta úlceras de decúbito, geralmente, não é devido à doença, mas à enfermagem”.

A úlcera de pressão pode ser definida como "uma área localizada de necrose celular que tende a desenvolver-se quando os tecidos moles são comprimidos entre uma proeminência óssea e uma superfície dura por um período prolongado de tempo" [2].

De acordo com o estudo de Fernandes [3], $40 \%$ dos pacientes em Centros de Terapia Intensiva (CTI) desenvolvem úlceras de pressão nas duas primeiras semanas de hospitalização, sendo consideradas como as complicaçóes comuns em pacientes com curto ou longo tempo de internação e em Unidades de Tratamento Intensivo (UTI) a incidência de úlceras de pressão em doentes cirúrgicos atinge o índice de $17 \%$. 
Um estudo desenvolvido por Bergstrom et al. [4] mostra que a incidência de úlceras de pressão apresentou-se significativamente maior em pessoas do sexo feminino do que do sexo masculino. Outro achado deste estudo, foi que pessoas de pele branca, em número consideravelmente maior, desenvolveram úlceras de pressão comparadas a pessoas negras. Os autores relatam também que a ocorrência de úlceras de pressão está associada a certas patologias e às intervençóes realizadas para a prevenção destas.

Geralmente, estão localizadas em áreas de proeminências ósseas (Gráfico 1) e ocorrem quando a pressão aplicada à pele, por algum tempo, é maior que a pressáo capilar normal $(32 \mathrm{mmHg} /$ arteríolas e $12 \mathrm{mmHg}$ /vênulas) [5].

Gráfico 1 - Distribuição percentual das úlceras de pressão segundo localização.

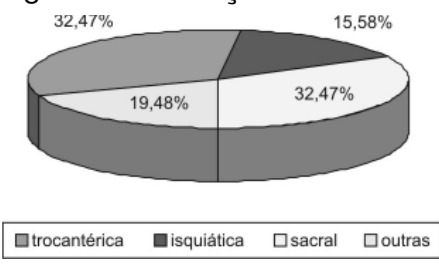

Fonte: Costa et al. [6].

Estas podem se desenvolver em 24 horas ou levar até 5 dias para sua manifestação. Todos os profissionais da área médica, responsáveis pelo acompanhamento do paciente devem estar familiarizados com os principais fatores de risco. Neste sentido, a observação das medidas profiláticas para eliminar forças de pressão contínua, cisalhamento ou fricção é de vital importância para evitar a formação de úlceras [6].

A etiologia da úlcera de pressão ainda não está totalmente esclarecida, mas sabe-se que a pressáo contínua sobre a pele leva a fenômenos isquêmicos associados à deficiência de nutrientes e conseqüentemente necrose tecidual. Pode-se afirmar que esta seja multidimensional, e os fatores apresentados como mais importantes são a imobilidade e a diminuição da percepção sensorial, que levam ao excesso de pressão e isquemia.

Porém, constata-se que são muitos os fatores de risco que podem predispor ao paciente a úlcera de pressão [5]. Estas podem ser provocadas por fatores internos e externos [7]:

1. Fatores externos: São aqueles que estão relacionados ao mecanismo de lesão, influenciado a tole- rância tissular pelo impedimento da circulação sobre a superfície da pele, e que refletem o grau em que a pele é exposta. São eles:

1. Pressão: como já foi citado, é o fator mais importante - o tecido mole é comprimido entre uma saliência óssea e uma superfície dura. Ocorre uma pressão maior que a capilar, causando isquemia.

1. Cisalhamento: ocorre quando o indivíduo desliza da cama - o esqueleto e os tecidos mais próximos se movimentam, mas a pele permanece imóvel. Um dos piores hábitos que pode ocasionar esse tipo de lesão é o de apoiar as costas na cabeceira da cama, o que favorece o deslizamento, causando dobras na pele.

1. Fricção: ocorre quando duas superfícies são esfregadas uma contra a outra. A forma mais comum de ocorrência desse tipo de problema é arrastar o cliente ao invés de levantá-lo, o que remove as camadas superiores das células epiteliais. A umidade piora os efeitos da fricção.

2. Fatores internos: Os fatores internos estão relacionados às variáveis do estado físico do cliente, que influenciam tanto na constituição e integridade da pele, nas estruturas de suporte ou nos sistema vascular e linfático que servem à pele e estruturas internas, quanto no tempo de cicatrização. Entre os fatores internos, pode-se incluir aqueles relacionados às condiçóes do cliente, tais como: condiçóes nutricionais; nível de consciência; idade avançada; incontinência urinária ou fecal; mobilidade reduzida ou ausente; peso corporal (menos tecido adiposo, menor proteção nas proeminências ósseas); doenças (diabetes, hipertensão, doença vascular periférica, câncer e outras); uso de medicamentos (antibióticos, corticóide, aminas, beta-bloqueadores e outros).

As úlceras eram classificadas, segundo o Centro Nacional de Dados sobre Lesão Medular como: Grau I - as lesôes são limitadas a epiderme e derme superficial; Grau II - as lesóes envolvem a pele em sua espessura total e o tecido celular subcutâneo; Grau III - as lesóes se estendem até o plano muscular e Grau IV - onde há destruição de todos os tecidos (partes moles) com acometimento de ossos ou articulaçóes [6].

Para aplicar está classificação com segurança, o enfermeiro deverá saber identificar a epiderme, a derme, o tecido subcutâneo e diferenciar o tecido 
granulado, músculo, tendóes e ossos.

De acordo com Jorge \& Dantas [8], a avaliação é definida como apreciação de uma situação na qual existem vários fatores norteadores e o primeiro passo para essa avaliação é o diagnóstico e determinação de um plano de cuidados de forma sistematizada.

A terapêutica no caso da úlcera de pressão por falta de mobilidade é demorada, ou seja, o tempo de convalescença é longo.

O estudo de caso hipotético, que será apresentado durante esta pesquisa, trata de um paciente de 34 anos que sofreu traumatismo raquimedular, tendo como causa um mergulho no rio causando fratura de $\mathrm{C} 4$ e $\mathrm{C} 5$, sendo diagnosticada tetraplegia.

De acordo com as consideraçóes de Defino [9], o mergulho em águas rasas representa uma importante causa de trauma raquimedular, tendo sido observados sessenta e nove casos entre 1989 a 1996, com o predomínio desse tipo de lesão em pessoas jovens do sexo masculino, principalmente durante o verão.

Estes pacientes ficam acamados e imóveis por um longo período, o que os torna suscetíveis à úlcera de pressão.

Conforme acrescenta Corrêa [10]:

"A imobilidade é definida como inabilidade ou a diminuição da capacidade de mudança de posição corporal. Ela pode ter longa duração ou náo, dependendo dos fatores a que está condicionada. Quanto maior o período de imobilidade mais danos ao organismo. Uma ou mais pessoas podem ter o mesmo nível de imobilidade, porém cada uma delas perceberá e reagirá de forma particular, singular, envolvendo o conhecimento que tem a respeito do problema e do tratamento dispensado, os fatores psicológicos e sociais, a motivaçáo para a cura e a reação do organismo. Podendo produzir três mudanças críticas na capacidade de adaptaçáo do sistema cardiovascular na condução do sangue para os capilares. São elas: controle vasomotor, retorno venoso ao coraçáo e estase venosa. A formação de trombose venosa nesta situação é comum, pois a estase venosa e a desidrataçáo podem levar a um quadro de hipercoagulabilidade do sangue".

Dessa forma, o enfermeiro deve estar atento sobre a forma de assegurar o cuidado com a úlcera de pressão, dando orientaçóes sobre como realizar o curativo.

Por este motivo, o objetivo deste artigo é elaborar uma rotina de enfermagem aplicada ao paciente com úlcera de pressão, destacando a seleção da técnica de curativo que deve ser adotada em cada etapa do tratamento, pautando-se por critérios que privilegiem uma conduta individualizada.

\section{Material e método}

O estudo se desenvolveu a partir de uma pesquisa descritiva, que, segundo Andrade [11] afirma, na pesquisa descritiva, os fatos são observados, registrados, atualizados, classificados e interpretados, sem que o pesquisador interfira neles.

Gil [12] acrescenta que esse tipo de pesquisa tem como objetivo primordial a descrição das características de determinada população, fenômeno ou o estabelecimento de relação entre variáveis.

Quanto à abordagem, trata-se de um estudo qualitativo, que segundo Gomes apud Andrade [11], responde a uma questão muito particular, se preocupa, nas ciências, com um nível de realidade que não pode ser quantificada, ou seja, trabalha com o universo de significados, motivos, aspiraçóes, crenças, valores e atitudes, o que corresponde a um espaço mais profundo das relaçóes, dos processos e dos fenômenos que podem se reduzidos à operacionalização da variável.

O método de pesquisa adotado é o hipotéticodedutivo, aplicado por meio de um estudo de caso, a fim de ilustrar como deve ser a conduta do enfermeiro com relaçáo aos cuidados do paciente com úlcera de pressão.

\section{Procedimento de coleta de dados}

A elaboração do instrumento de coleta de dados foi desenvolvida em duas etapas:

1) Primeira etapa: Elaborou-se um suposto roteiro acerca do assunto. Para tal, buscou-se suporte teórico em literatura específica.

2) Segunda etapa: Para a elaboração da segunda parte do instrumento foi realizado um fichamento de todo o material pesquisado pertinente para identificação e categorização das condiçôes predisponentes (ou fatores associados) e dos fatores de risco intrínsecos e extrínsecos relacionados com a formação de úlcera de pressão, como também, os métodos de tratamento e curativos. 


\section{Resultados e discussão}

Paciente J.S.P., 34 anos, deu entrada no HEMB, vítima de traumatismo raquimedular, sofrida quando mergulhava, com fratura de $\mathrm{C} 4 \mathrm{e}$ C5, déficit, motor e sensitivo, sendo submetido à descompressão medular cervical. Evolui com quadro compatível com diagnóstico de tetraplegia.

No $9^{\circ}$ dia de internaçáo, o paciente apresenta úlcera de decúbito na regiáo sacra de grau I, o que corresponde à área de eritema que náo desaparece com pressáo, temperatura da pele elevada, tecidos macios e congestionados. Posteriormente, as úlceras também surgiram nas regióes trocantérica direta e esquerda, maleolar direita e esquerda, calcária direita e esquerda e tibial esquerda.

Pode-se observar, durante a avaliação clínica, que os problemas apresentados pelo cliente, os quais podem estar associados ao aparecimento de úlcera de pressão, são: deficiência nutricional, anemia e distúrbios metabólicos.

Observando-se também, outros fatores associados a essa afecção do paciente acamado, abordados na literatura existente, como, por exemplo:

- Umidade aumentada: o contato prolongado com a umidade devido à transpiração, urina, fezes ou líquido de drenagem produz a maceração da pele. A pele reage às substâncias causticas nessas secreçôes e tende a romper-se. Uma vez rompida a pele, a área é invadida por microorganismos e a infecção acontece.

- Imobilidade: o aparecimento da úlcera está diretamente ligado à duração da imobilidade. Se esta for prolongada, ocorre necrose tissular e trombose de pequenos vasos. As áreas de proeminência óssea são mais suscetíveis ao desenvolvimento da ulceração porque são cobertas por pele e pequena quantidade de tecido subcutâneo.

- Atrito - tracionamento: as forças mecânicas contribuem para o desenvolvimento de úlcera de pressão. As úlceras, devido ao atrito e traça, ocorrem quando o paciente desliza para a parte inferior da cama ou quando é movimentado ou posicionado inadequadamente. Os músculos espásticos e a paralisia aumentam a vulnerabilidade às relacionadas com atrito e tração.

Potter \& Perry [13] consideram a depressão também um fator de risco. A depressão é um estado emocional anormal caracterizado por sentimentos exagerados e desproporcionais de tristeza, melancolia, desânimo, inutilidade, vazio e desesperança.
Pode ser resultante de uma preocupaçáo a respeito da saúde ou de necessidades familiares e financeiras, atuais ou futuras. Uma vez que a imobilização impede que o paciente realize suas atividades diárias, ele tem mais tempo para se preocupar com a sua incapacidade, o que pode rapidamente aumentar a depressáo, causando isolamento. Tendo em vista os fatores de risco apresentados, a conduta adotada deve contemplar os aspectos em que sáo considerados de modo amplo tanto o paciente quanto a ferida, pois, para Potter \& Perry [13], pelo processo de enfermagem, o profissional avalia as necessidades fisiológicas, psicossociais e de desenvolvimento, diagnostica problemas reais ou potenciais relacionados à imobilização, planeja e dá assistência para suprir as necessidades do paciente e evita ou resolve problemas. Como os efeitos da imobilidade podem ser prolongados ou permanentes, a assistência a esses pacientes é um desafio para o profissional.

$\mathrm{O}$ quadro grave apresentado pelo paciente em questão, associado aos fatores de risco, contribuiu para que as úlceras atingissem o grau IV de evolução, que se caracteriza por estender-se até as estruturas subjacentes, como indicativa de infecção. Era possível se localizar, ainda, bolsas profundas de infecção sob a pele ao redor da lesáo e em alguns pontos, exposição óssea. No decorrer do tratamento, foram utilizadas as seguintes opçôes terapêuticas:

- Carvão ativado: se mostra eficaz na absorção de substâncias químicas liberadas pelas feridas fétidas e é o único curativo bactericida. Apresenta grande vantagem se associado a outros produtos, como ácidos graxos essenciais e alginatos.

- Alginato: curativo interativo, pois sua estrutura se altera à medida que ele reage com a ferida. Quando absorve o exsudato, o curativo muda sua estrutura fibrosa para a consistência de gel. É apropriado para feridas com exsudação moderada a grande e pode exigir um curativo secundário.

- Gaze náo-aderente: preserva o tecido em granulação e não adere ao leito da ferida. É indicada para áreas cruentas pós-trauma e contra-indicada para ferida com secreção purulenta.

- Ácidos graxos essenciais (AGE Dersani ${ }^{\circledR}$ ): mantém a integridade da epiderme, uma vez que tornam a membrana celular mais resistente aos estímulos agressivos, atuando como emoliente, acelerando o processo de granulação.

- Hidrogéis: têm capacidade de absorver o exsudato e de hidratar feridas ressecadas, como escaras necróticas facilitando, assim, o desbridamento. 
Podem ser utilizados em feridas com exsudação de baixa a moderada e em pequenas cavidades. Exigem curativos secundários.

- Terapia por vácuo: é utilizada através de pressão negativa da ferida, estimulando o fluxo sanguíneo e uma rápida granulação. A pressão é feita por um aparelho que contém uma esponja revestida por curativo-filme, com a finalidade de criar um selo hermético. A esponja é ajustada à ferida e se liga à bomba por meio de um receptáculo para coletar o exsudato.

A freqüência de troca dos curativos depende da indicação do fabricante bem como da necessidade de substituição. De acordo com Tashiro \& Murayama [14], o curativo deve ser trocado sempre que estiver úmido, já que a secreção irrita a pele e age como possível meio de cultura.

No paciente estudado havia, inicialmente, áreas de necrose, e optou-se pelo uso do curativo de carvão ativado, verificando-se melhora significativa e diminuição de tecido desvitalizado. Diante da alteração do quadro apresentado, com presença de apenas poucas áreas de necrose, tornou-se necessário modificar o tratamento já que o carvão ativado não está fisicamente adequado a lesóes pequenas, por não poder ser cortado.

Adotou-se um esquema à base de alginato de cálcio e hidrogel, que promovem desbridamento autolítico de tecido. Nesse estágio ainda não havia exposição óssea com o emprego dos curativos acima citados, o paciente apresentou boa evolução no início da fase de cicatrização tanto das úlceras maleolares direta e esquerda como das calcâneas direta e esquerda e da tibial esquerda e obteve alta hospitalar.

Houve re-internação, verificando-se piora significativa das lesóes, com aumento de extensão e profundidade, principalmente da regiáo sacra. Nesse momento, as áreas de exposição óssea foram protegidas com gaze não aderente e AGE, e voltou-se a utilizar carvão ativado nas áreas de necrose e secreção. Como a evolução não foi satisfatória, optou-se pelo emprego de novo tratamento (terapia por vácuo), através da qual se obteve melhora considerável das úlceras de pressão na região.

\section{Conclusão}

Ao realizar o levantamento bibliográfico para o estudo de caso, observou-se o quanto é importante que seja adotada uma rotina pré-estabelecida de técnicas e tipos de curativos para tratamento das úlceras de pressão em região sacra, visto que, a uniformização das ações contribuirá para o controle e acompanhamento adequados das lesões, propiciando melhor prognósticos ao paciente como contribuição para a facilitação das ações de enfermagem. Em face do exposto, sugere-se a utilização de uma escala que possibilite o acompanhamento da evolução das úlceras PRS e de um manual de rotinas que especifique o uso dos diversos tipos de curativos de que se dispóem na instituição e a seqüência ideal de evoluçáo da ferida.

Deve-se lembrar que existem novos produtos para utilizar no tratamento das úlceras de pressão cujos resultados são bastante eficazes. Porém, a indicação fica a critério do médico ou do profissional de enfermagem especializado.

Manter alguns cuidados com a pele do paciente também é fundamental. Atuando no alívio da pressão da pele, nas áreas de maior risco ou onde se têm ossos mais proeminentes. Estes cuidados podem ser realizados desde os primeiros momentos que o paciente ficou acamado, seja em casa ou no hospital.

Diante do exposto neste trabalho, pode-se dizer que os cuidados de enfermagem no paciente com úlcera de pressáo em regiáo sacra devem ser:

- Manter o colchão piramidal (caixa de ovo) sobre o colcháo da cama do paciente;

- Mudar sempre o paciente acamado de posição;

- Colocar travesseiros macios embaixo dos tornozelos para elevar os calcanhares;

- Colocar o paciente sentado em poltrona macia ou revestida com colcháo piramidal várias vezes ao dia;

- Quando sentado, mudar as pernas de posição, alternando as áreas de apoio;

- Manter alimentação rica em vitaminas e proteínas;

- Manter hidratação;

- Trocar fraldas a cada três horas, mantendo o paciente limpo e seco;

- Hidratar a pele com óleos e/ou cremes á base de vegetais;

- Utilizar sabonetes com pH neutro para realizar a limpeza da regiáo genital;

- Aplicar filme transparente, cremes ou loçóes à base de AGE nas áreas de risco aumentado para lesões;

- Manter a limpeza das roupas de cama, bem como mantê-las secas e bem esticadas. 


\section{Referências}

1. Rabeh SAN. Úlcera de pressão: a clarificação do conceito e estratégias para divulgação do conhecimento na literatura de enfermagem [Dissertação]. Ribeirão Preto: Universidade de Sáo Paulo, 2001. 195p.

2. Rangel EML, Prado KG, Machry AL, Rustici ACF, Caliri MHL. Prática de graduandos de enfermagem referentes a prevenção e tratamento de úlcera de pressáo. Rev Latinoam Enfermagem 1999;7(2):89-90.

3. Fernandes LM. Úlcera de pressão em pacientes críticos hospitalizados. Uma revisão integrativa da literatura [dissertação]. Ribeirão Preto: Universidade de São Paulo; 2000. 186p.

4. Bergstrom N, Allman RM, Carlson CE, Eaglstein E, Frantz RA, Garber SL. Pressure ulcers in adults: prediction and prevention. Quick Reference Guide for Clinicians No. 3. Rockville: Agency for Health Care Policy and Research, Public Health Service; 1992.

5. Silva RCL, Figueiredo NMA, Meireles IB, eds. Feridas: fundamentos e atualizaçôes em enfermagem. São Paulo: Yendis; 2007.
6. Costa MP, Sturtz G, Costa FPP, Ferreira MC, Barros Filho TEP. Epidemiologia e tratamento das úlceras de pressão: experiência de 77 casos. Acta Ortop Bras 2005;13(3) 124-33.

7. Dealey C. Cuidando de feridas: um guia para as enfermeiras. São Paulo: Atheneu; 1996.

8. Jorge AS, Dantas SRPE. Abordagem multiprofissional do tratamento de feridas. São Paulo: Atheneu; 2003.

9. Defino HLA. Trauma raquimedular. Medicina 1999;32:388-400.

10. Corrêa KP. Verificação dos resultados da aplicação do laser de baixa potência, GaAlAs, $830 \mathrm{~nm}$, em úlcera de pressão de paciente portador de seqüela de traumatismo raquimedular: Estudo de caso [TCC]. Cascavel: Universidade Estadual do Oeste do Paraná; 2003.

11. Andrade $\mathrm{MN}$. Introdução a metodologia do trabalho científico. 6a ed. São Paulo: Atlas; 2003.

12. Gil AC. Como elaborar projeto de pesquisa. $3^{a}$ ed. São Paulo: Atlas; 2002.

13. Potter PA, Perry AG. Grande tratado de enfermagem prática. $3^{a}$ ed. São Paulo: Santos; 1998.

14. Tashio MTO, Murayama SPG. Assistência de enfermagem em ortopedia e traumatologia. São Paulo: Atheneu; 2001. 